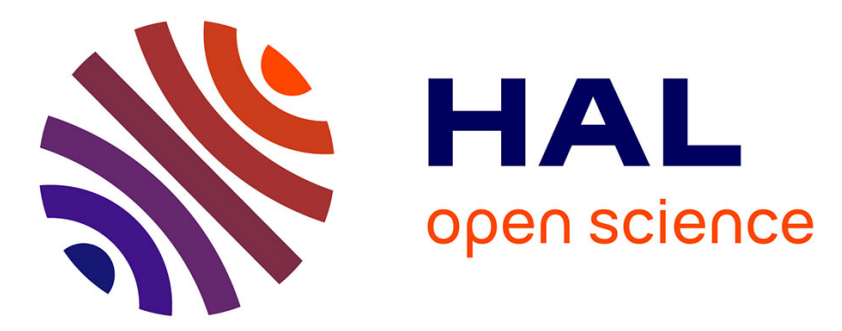

\title{
2E1 Ar17+ decay and conventional radioactive sources to determine efficiency of semiconductor detectors
}

Emily Lamour, Christophe Prigent, Benjamin Eberhardt, Jean-Pierre Rozet, Dominique Vernhet

\section{- To cite this version:}

Emily Lamour, Christophe Prigent, Benjamin Eberhardt, Jean-Pierre Rozet, Dominique Vernhet. 2E1 Ar17+ decay and conventional radioactive sources to determine efficiency of semiconductor detectors. Review of Scientific Instruments, 2009, 80 (2), pp.023103. 10.1063/1.3077284 hal-00362327

\section{HAL Id: hal-00362327 https://hal.science/hal-00362327}

Submitted on 17 Feb 2009

HAL is a multi-disciplinary open access archive for the deposit and dissemination of scientific research documents, whether they are published or not. The documents may come from teaching and research institutions in France or abroad, or from public or private research centers.
L'archive ouverte pluridisciplinaire HAL, est destinée au dépôt et à la diffusion de documents scientifiques de niveau recherche, publiés ou non, émanant des établissements d'enseignement et de recherche français ou étrangers, des laboratoires publics ou privés. 


\title{
$2 \mathrm{E} 1 \mathrm{Ar}^{17+}$ decay and conventional radioactive sources to determine efficiency of semiconductor detectors
}

Emily Lamour ${ }^{1}$, Christophe Prigent, Benjamin Eberhardt, Jean Pierre Rozet, and

Dominique Vernhet

Université Pierre et Marie Curie - Paris 6, UMR 7588, INSP, 140 rue de Lourmel, Paris, F-75015 France, and

CNRS, UMR7588, INSP, Campus Boucicaut, Paris, F-75015 France

\begin{abstract}
Although reliable models may predict the detection efficiency of semiconductor detectors, measurements are needed to check the parameters supplied by the manufacturers namely the thicknesses of dead layer, beryllium window and crystal active area. The efficiency of three silicon detectors has been precisely investigated in their entire photon energy range of detection. In the 0 to a few $\mathrm{keV}$ range, we have developed a new method based on the detection of the $2 E 1$ decay of the metastable $\operatorname{Ar}^{17+} 2 \mathrm{~s} \rightarrow 1 \mathrm{~s}$ transition. Very good theoretical knowledge of the energetic distribution of the $2 E 1$ decay mode enables precise characterization of the absorbing layers in front of the detectors. In the high-energy range $(>10 \mathrm{keV})$, the detector crystal thickness plays a major role in the detection efficiency and has been determined using a ${ }^{241}$ Am source.
\end{abstract}

\footnotetext{
${ }^{1}$ Corresponding author. emily.lamour@insp.jussieu.fr
} 


\section{INTRODUCTION}

Due to their excellent compromise between resolution and detection efficiency, semiconductor detectors (Ge, $\mathrm{Ge}(\mathrm{Li}), \mathrm{Si}(\mathrm{Li}), \mathrm{Si}, \mathrm{HPGe}$ and so on) are commonly used for quantitative analysis of X-ray emission. Model of their response function and detection efficiency is entirely based on the knowledge of photon-matter processes, i.e., mainly the photoelectric effect and the Compton scattering, and allows to reach a precision of a few $\%$ in absolute X-ray yield measurements. Being easy to handle, these solid-state detector have brought, for several decades, meaningful results in various fields of interest from particle to solid-state physics. In our group, we routinely employed detectors with $\mathrm{Si}(\mathrm{Li})$ and Si crystals, either to determine absolute populations of excited states of highly charged ions produced during ion-solid interaction ${ }^{1,2}$, or to quantify the production rates of X-ray emission when rare gas clusters are submitted to strong optical fields 3 .

The overall accuracy of these measurements strongly relies on both the response function and detection efficiency of those detectors. Nowadays, the response functions are well understood and simulations, frequently based on Monte Carlo methods, reproduce well all the spectral features whatever the incident energy ${ }^{4,5,6,7,8}$. Below a few $\mathrm{keV}$, the low energy tail accompanying the full absorption energy peak is known to be mainly due to incomplete charge collection effects ${ }^{5,6,7}$ that occur at low incident photon energies. For much higher incident photon energies (above a few tens of $\mathrm{keV}$ ), a small fraction of photons interacts with the quasi-free electrons of the detector material and is scattered, losing part of their energy in the detector or escaping from the detector. These Compton 
processes induce a continuum background ${ }^{4,8}$ under the main peaks, which result from the photoelectric effect. The energy-efficiency relationships have been largely studied both experimentally and theoretically $9,10,11,12,13$. The most common experimental techniques exploit either various calibrated radioactive samples providing X-ray and $\gamma$ lines from 3 to $60 \mathrm{keV}^{4,9,13}$, or monochromatic $\mathrm{X}$-ray synchrotron radiation from 0.1 to a few $\mathrm{keV}^{6,7}$ provided by storage rings.

In this paper, we present a new approach to determine the detection efficiency in the low energy range. It is based on the accurate theoretical knowledge of the line shape of the single-photon energy distribution of the two-photon decay mode (2E1) of the $\mathrm{Ar}^{17+} 2 \mathrm{~s}$ metastable state, which exhibits a broad energetic distribution from 0 to $3 \mathrm{keV}^{14}$. This measurement enables the determination of absorbing layers in front of the active area of detectors such as beryllium or organic windows, metallic contacts and dead layers when present. Moreover, the thickness of the active crystal area of detectors has been deduced from measured detection efficiencies above $10 \mathrm{keV}$, using a ${ }^{241} \mathrm{Am}$ source. Measurements for three different solid-state detectors used have been performed: a $\mathrm{Si}(\mathrm{Li})$ detector from ORTEC Inc. (USA) and two silicon drift detectors, a XFlash model from RONTEC GmbH (Germany) and the other supplied by KETEK GmbH (Germany).

The paper is organized as follows. In section II, specifications of each detector are presented and basic points to calculate their total transmission are reviewed. In section III, we present the experimental methods to determine the thickness of different components which play a significant role in the detection efficiency. Below $10 \mathrm{keV}$, we 
make use of the deexitation of highly charged ions interacting with gaseous and solid targets as well as fluorescence emission induced by electron impact onto various solid foils (section II.A.). Above $10 \mathrm{keV}$, we report on results obtained with a ${ }^{241} \mathrm{Am}$ radioactive source (section II.B). The last section summarizes the comparison of detector characteristics extracted from experimental data with those supplied by the manufacturers. We discuss the entire set of results presenting the full efficiency curve over the whole energy range of detection. In conclusion, the sensitivity of the two methods used is emphasized.

\section{DETECTOR CHARACTERISTICS AND CALCULATION OF DETECTION EFFICIENCIES}

\section{A. Detector characteristics}

The specifications given by each manufacturer are summarized in table I. All the three semiconductor detectors can be used under good vacuum conditions $\left(\sim 10^{-7} \mathrm{mbar}\right)$ and are sealed by a beryllium window. The $\mathrm{Si}(\mathrm{Li})$ detector from ORTEC Inc. (USA) is equipped with the thickest crystal giving access to efficiencies larger than $10 \%$ up to $70 \mathrm{keV}$ while the $25 \mu \mathrm{m}$ Be window thickness limits the detection efficiency below $1 \mathrm{keV}$. A crystal diameter of $10 \mathrm{~mm}$ insures a large solid angle. Other specific features are a gold layer acting as a front electrode and a thin dead layer of $0.1 \mu \mathrm{m}$. Finally, the ensemble is mounted on a liquid nitrogen cryostat for cooling purpose. With this first generation technique, a $180 \mathrm{eV}$ FWHM resolution at $5.9 \mathrm{keV}$ is obtained. The two other 
detectors are based on SDD (silicon drift detector) technique ${ }^{15}$, which combines a large sensitive area (the entire $\mathrm{Si}$ wafer is sensitive to radiations) with a small output capacitance due to a sub-millimetre crystal thickness. They both can afford high counting rates and reach a FWHM resolution of $140 \mathrm{eV}$ at $5.9 \mathrm{keV}$, which is significantly better than for the ORTEC detector. A Peltier element cools them down to a working temperature of around $-10{ }^{\circ} \mathrm{C}$. The RONTEC XFlash detector has a thinner crystal $(300 \mu \mathrm{m})$ combined to the thinnest Be window $(8 \mu \mathrm{m})$. This leads to a detection range (efficiency better than $10 \%$ ) extending from $850 \mathrm{eV}$ to $25 \mathrm{keV}$. The KETEK detector (most recent generation of SDD detectors), equipped with a slightly thicker crystal (450 $\mu \mathrm{m}$ ) and a beryllium window of $25 \mu \mathrm{m}$, has a detection range of 1 to $30 \mathrm{keV}$. In addition, its much larger diameter, i.e., $10 \mathrm{~mm}$ instead of $2 \mathrm{~mm}$ for the RONTEC detector, insures a much better solid angle. In the following, the different set of specifications provided by the manufacturers for each detector will be introduced as parameters in the calculation and compared to our measurements.

\section{B. Calculation of the total transmission of a semiconductor detector}

The absolute detection transmission $\mathrm{T}$ is simply given by the product of the solid angle $(\Omega / 4 \pi)$ with the quantum efficiency $\varepsilon(E)$ :

$\mathrm{T}=\varepsilon(\mathrm{E}) \times \frac{\Omega}{4 \pi}$. 
The quantum efficiency corresponds to the ratio of detected photons over the number of incident photons and depends drastically upon the incident photon energy (E): when raising the X-ray energy, the efficiency first increases to reach a maximum, and then decreases reaching "zero" when the X-ray energy is so high that radiation crosses the active volume without interaction. The following simple formula reproduces this behavior:

$\varepsilon(E)=\left(1-\exp \left[-\mu_{\mathrm{sz}}(\mathrm{E}) \times \mathrm{x}_{\mathrm{sz}}\right]\right) \times \exp \left[-\sum_{\mathrm{i}}\left(\mu_{\mathrm{i}} \times \mathrm{x}_{\mathrm{i}}\right)\right]$,

The first term corresponds to the intrinsic efficiency of the detector, where $\mu_{\mathrm{sz}}$ stands for the photoelectric absorption coefficient in the sensitive zone of crystal thickness $\mathrm{x}_{\mathrm{sz}}$ (generally $\mathrm{x}_{\mathrm{sz}}$ is not well known a priori). $\mu_{\mathrm{i}}$ and $\mathrm{x}_{\mathrm{i}}$ denote respectively the absorption coefficients and thicknesses of the different absorbers lying in front of the active region of the crystal such as the Be window $\left(\mu_{\mathrm{Be}}, \mathrm{x}_{\mathrm{Be}}\right)$, the Si dead layer $\left(\mu_{\mathrm{dl}}, \mathrm{x}_{\mathrm{dl}}\right)$ and/or the gold layer $\left(\mu_{\mathrm{Au}}, \mathrm{x}_{\mathrm{Au}}\right)$. Usually, an additional correction factor has to be considered $\mathrm{F}_{\text {escape }}=\left(1-\mathrm{P}_{\text {escape }}\right)$ that corresponds to the escape peak correction where $\mathrm{P}_{\text {escape }}$ stands for the probability to get such event. This peak appears when a $\mathrm{K}_{\alpha}$ fluorescence photon, first created by photoelectric effect, escapes from the active area. The incident photon with an initial energy $E$ will be then detected at the energy $E-E_{K}$ where $E_{K}$ is the $K$-shell binding energy of the crystal constituent ${ }^{9} . \mathrm{P}_{\text {escape }}$ is given by: 
$\mathrm{P}_{\text {escape }}=\frac{1}{2} \times \frac{\mu_{\mathrm{E}}^{\mathrm{K}}}{\mu_{\mathrm{E}}} \times \omega_{\mathrm{K}} \times\left[1-\frac{\mu_{\mathrm{S}}}{\mu_{\mathrm{E}}} \ln \left(1+\frac{\mu_{\mathrm{E}}}{\mu_{\mathrm{S}}}\right)\right]$.

$\mu_{\mathrm{E}}^{\mathrm{K}}$ is the K-shell photoelectric absorption coefficient. $\mu_{\mathrm{E}}$ and $\mu_{\mathrm{S}}$ stand for the total absorption coefficients of the incident photons and the $\mathrm{K}_{\alpha} \mathrm{X}$-rays emitted by crystal atoms respectively; $\omega_{\mathrm{K}}$ is the $\mathrm{K}$-shell fluorescence yield. For $\mathrm{Si}$ or $\mathrm{Si}(\mathrm{Li})$ detectors, $\mathrm{F}_{\text {escape }}$ gives rise to a correction of the detection efficiency smaller than $2 \%$ while it can reach more than $10 \%$ for Ge crystals.

It is worth to recall that detection efficiency is very sensitive to absorber thicknesses for incident photon energies less than $10 \mathrm{keV}$. Especially, the beryllium thickness affects strongly the efficiency in the 0 to $3 \mathrm{keV}$ energy range while the dead layer and gold contact thicknesses play a major role between 2 and $6 \mathrm{keV}$. For photon energies greater than $10 \mathrm{keV}$, within the Be window thickness range considered here, only the thickness of the sensitive zone may dramatically change the efficiency. Consequently, we have developed two methods to experimentally test the efficiency of our three silicon detectors: one sensitive to the characteristics of absorbers lying in front of the active area and the other allowing us to determine the crystal thickness.

\section{METHODS OF MEASUREMENT AND RESULTS BELOW AND}

\section{ABOVE $10 \mathrm{keV}$}




\section{A. Low energy region below $10 \mathrm{keV}$}

Precise measurements of the detection efficiency in the low energy range $(<3 \mathrm{keV})$ have been obtained by recording photons coming from the deexcitation of the $\operatorname{Ar}^{17+} 2 \mathrm{~s}$ metastable state. Briefly summarized, a beam-foil spectroscopy experiment has been performed on the LISE (Ligne d'Ions Super Epluchés) facility at GANIL (Grand Accélérateur National d'Ions Lourds - Caen, France) ${ }^{1,2}$. Fully stripped 13.6 MeV/amu $\mathrm{Ar}^{18+}$ ions, directed onto thin solid carbon targets of a few $\mu \mathrm{g} / \mathrm{cm}^{2}$ and gaseous targets $\left(\mathrm{N}_{2}\right.$ and $\mathrm{CH}_{4}$ ) lead to the production of excited $\mathrm{Ar}^{17+}$ ions by the single capture process. Most of the populated exited states decay very fast via single photon modes towards the ground state, i.e., within a few $10^{-14} \mathrm{~s}$ for the $\mathrm{np}$ states (the cross section of the capture process being maximum in $n=2)$. On the contrary the $2 \mathrm{~s}$ state has a long lifetime $\left(3.5 \times 10^{-9} \mathrm{~s}\right.$ for $\left.\mathrm{Ar}^{17+}\right)$. At a projectile velocity of $13.6 \mathrm{MeV} / \mathrm{amu}$, this lifetime corresponds to a propagation distance of $173.6 \mathrm{~mm}$. Consequently, the deexcitation of such a long lifetime state may be easily recorded by a solid-state detector placed at $90^{\circ}$ with respect to the beam axis and at a distance of a few centimetres behind the target. A specific collimation system, mounted in front of the detector, ensures good spatial resolution and allows us to know precisely the detection solid angle.

The $2 s$ state has two decay modes: a two-photon mode (2E1) and a single-photon magnetic mode (M1) with branching ratios respectively of $97 \%$ and $3 \%{ }^{14}$ for $\mathrm{Ar}^{17+}$. In the $2 E 1$ decay mode, two photons are simultaneously emitted sharing the $2 s \rightarrow 1 s$ transition energy $(\mathrm{E}(2 s \rightarrow 1 s)=3.321 \mathrm{keV}$ in the projectile frame, i.e., $3.273 \mathrm{keV}$ in the laboratory 
frame). For such medium $\mathrm{Z}$ ion, the well known energy distribution ${ }^{14}$ is then found to be a broad continuum from 0 to $\mathrm{E}(2 s \rightarrow 1 s)$ and symmetric with respect to half of the total energy $\mathrm{E}(2 s \rightarrow 1 s)$. Consequently, this transition provides a way to test the detection efficiency continuously at very low energy by recording a single spectrum. More specifically, it affords to achieve precise measurements of the Be entrance window of the detector. Figure 1 shows that the $2 E 1$ energy distribution is dramatically changed when varying the Be thickness while the sensitivity to the dead layer appears to play a role above $1.839 \mathrm{keV}$, i.e., the Si K-shell threshold energy.

We have analyzed 35 spectra recorded by the RONTEC detector placed at a $50 \mathrm{~mm}$ distance behind gaseous targets and solid foils of different thicknesses ${ }^{2}$. Precise determination of the experimental $2 E 1$ line shape has been achieved since only total counts change from one spectrum to the other. Figure 2 presents a typical spectrum obtained for a $\mathrm{N}_{2}$ gaseous target. We can easily distinguish the $2 E 1$ photon decay emission from the $M 1$ line. Additionally, a small peak at $1.74 \mathrm{keV}$ is visible, coming from the $\mathrm{K}_{\alpha} \mathrm{Si}$ fluorescence. Together with the experimental spectrum, we present plots taking into account the calculated efficiency using equation 2 and the convolution of the theoretical energy distribution with detector resolution (see Fig. 2). Those fits, which have been calculated for a given dead layer and different thicknesses of the entrance Be window, show clearly that a $8 \mu \mathrm{m}$ Be thickness, as specified by the company, is too thin to reproduce the recorded emission. The best fit of the $2 E 1$ line below $1.7 \mathrm{keV}$ is obtained with a Be thickness of $15 \pm 1 \mu \mathrm{m}$ and an unexpected dead layer of $0.07 \mu \mathrm{m}$ to account for the observed Si fluorescence peak (no dead layer has been specified by the manufacturer 
see table I). To illustrate this effect, we present in Fig. 3 a comparison with and without dead layer for the same Be window thickness (namely $15 \mu \mathrm{m}$ ). The introduction of a $\mathrm{Si}$ dead layer thickness, even very small, visibly improves the agreement with photon emission spectrum recorded by the RONTEC detector. We stress the fact that, the whole range of energies between 0 and $3 \mathrm{keV}$ being covered at once with the $2 E 1$ spectral distribution, unprecedented accuracies can be obtained compared to methods using a set of monochromatic lines.

These results have been confirmed by measurements of fluorescence yield induced by electron impact. A $10 \mathrm{keV}$ electron beam is directed at $90^{\circ}$ onto targets of different elements; i.e., foils or powders of $\mathrm{NaNO}_{3}, \mathrm{MgF}_{2}, \mathrm{KClAl}, \mathrm{Si}, \mathrm{CaF}_{2}, \mathrm{Sc}$ and stainless steel $(\mathrm{CrFeNi})$. The production of vacancies in atomic inner-shells of these various components gives rise to the generation of characteristic X-rays. The well known full efficiency calibration of one detector allows then to calibrate others quite rapidly. Two Xray detectors, among which one is calibrated, are symmetrically placed at $30^{\circ}$ from the electron beam direction to record the emitted X-rays. Circular diaphragms of welldefined diameter ${ }^{16}$ are positioned in front of the detectors to monitor the solid angle $\Omega$. The whole experimental set-up is under good vacuum $\left(<10^{-6} \mathrm{mbar}\right)$. Since one of the detectors (det0) is fully calibrated in efficiency, the detection efficiency of the other detector (det1) is simply given by:

$$
\varepsilon_{\operatorname{det} 1}=\frac{\mathrm{N}_{\operatorname{det} 1}^{K \alpha}}{N_{\operatorname{det} 0}^{K \alpha}} \times \frac{\Omega_{\operatorname{det} 0}}{\Omega_{\operatorname{det} 1}} \times \varepsilon_{\operatorname{det} 0}
$$


where $\mathrm{N}_{\operatorname{det} 1}^{\mathrm{K \alpha}}$ and $\mathrm{N}_{\operatorname{det} 0}^{\mathrm{K} \alpha}$ stand for the number of counts (corrected by the acquisition dead time of the corresponding channel) of a given $\mathrm{K}_{\alpha}$ line recorded by each detector. Beside crossed check measurements of the efficiency of the RONTEC detector, a full calibration of the KETEK detector has then been achieved. Moreover, we have performed measurements of the $\mathrm{Mn} \mathrm{K}_{\alpha}$ line emitted by a ${ }^{55} \mathrm{Fe}$ source to enlarge the number of experimental data. As shown in Fig. 4, the experimental efficiencies measured by this method in the $0-6 \mathrm{keV}$ range are fully consistent with those obtained via the $2 E 1$ energy distribution; although they are not so accurate (the error bars for X-ray energy above 2 $\mathrm{keV}$ are much larger). Nevertheless, the fluorescence measurements give access to the thickness of the Be window of the KETEK detector, which is found larger than expected (34 $\mu \mathrm{m})$ with an uncertainty less than $10 \%$.

Same complete studies had been performed previously with the ORTEC detector (see spectra in Ref 1) and the specifications provided by the manufacturer were found to be much more accurate as summarized at the end of the paper (see table III).

\section{B. High energy region above $10 \mathrm{keV}$}

The detection efficiency in the photon energy regime above $10 \mathrm{keV}$ is sensitive only to the thickness of the crystal active area $\left(\mathrm{x}_{\mathrm{sz}}\right)$ as discussed in section II. In this region, the equation (2) simplifies to $\varepsilon(E)=1-\exp \left[-\mu_{\mathrm{sz}}(\mathrm{E}) \times \mathrm{x}_{\mathrm{sz}}\right]$. Evaluation of crystal thickness can be merely obtained by comparing, on the same spectrum, the number of counts of two peaks at different energies, provided relative emission probabilities of the corresponding transitions are well established. We have set a radioactive ${ }^{241} \mathrm{Am}$ source in 
front of each detector and recorded the ${ }^{237} \mathrm{~Np} \mathrm{~L} X$ lines and $\gamma$-rays whose energies range from 10 to $60 \mathrm{keV}$, coming from alpha decay of ${ }^{241} \mathrm{Am}$ atoms. The interest of using such a source lies in the precise knowledge of emission probabilities of almost 20 transitions ${ }^{17}$, 18, 19. In practice, the recorded spectrum is characterized by four groups of $\mathrm{Np} \mathrm{X}_{\mathrm{L}}$ emission lines, i.e., $\mathrm{L}_{1}, \mathrm{~L}_{\alpha}, \mathrm{L}_{\beta}$ and $\mathrm{L}_{\gamma}$ and four main gamma rays as shown in Fig 5 where a spectrum recorded by the ORTEC detector is displayed. Since the crystal active area is much thinner for the RONTEC and KETEK detectors, only the first $\gamma$-ray at $26.35 \mathrm{keV}$ is observed with enough statistics and the contribution of Compton scattering background is also much lower. In Fig. 6, this background has been subtracted under each group of lines using a linear fit so as to extract the photoelectric efficiency from the intensity.

In table II, transition energies and corresponding branching ratios ( $\left.\mathrm{I}_{\text {Line }}\right)$ normalized to the $\mathrm{L}_{\alpha}$ line are reported. In order to reduce the statistical error bars, the $\mathrm{L}_{\alpha}$ line has been chosen as reference since it is the most intense peak recorded by our three detectors. The relative detection efficiency $\left(\varepsilon_{\mathrm{Line}} / \varepsilon_{\mathrm{L} \alpha}\right)$ can be determined through the following simple equation:

$\frac{\varepsilon_{\text {Line }}}{\varepsilon_{\mathrm{L}_{\alpha}}}=\frac{\mathrm{N}_{\text {Line }}}{\mathrm{N}_{\mathrm{L}_{\alpha}}} \times \frac{\mathrm{I}_{\mathrm{L}_{\alpha}}}{\mathrm{I}_{\text {Line }}}$.

where $\mathrm{N}_{\mathrm{Line}}$ and $\mathrm{N}_{\mathrm{L} \alpha}$ are the number of counts of each line.

An enlargement of the 10 to $25 \mathrm{keV}$ energy region is presented in Figure 6 for the ORTEC and the RONTEC detectors allowing us to illustrate the strong dependence of the ratio $\mathrm{N}_{\text {line }} / \mathrm{N}_{\mathrm{L} \alpha}$ with the type of detector due to the difference of crystal thickness. We can 
clearly see for instance that the detection efficiency of the $\mathrm{L}_{\beta}$ line is much higher for the ORTEC than for the RONTEC detector.

The experimental $\left(\varepsilon_{\mathrm{Line}} / \varepsilon_{\mathrm{L} \alpha}\right)$ values obtained by this method and the corresponding fitted crystal thickness $\left(\mathrm{x}_{\mathrm{sz}}\right)$ are presented in table II. It is worth mentioning that gamma rays with energies higher than $30 \mathrm{keV}$ are observable only on the spectrum recorded with the ORTEC detector (see Fig 5) since for the others, the detection efficiency is around $4 \%$ at $30 \mathrm{keV}$ reaching almost "zero" above $60 \mathrm{keV}$.

Outcomes of this method are illustrated in figure 7 where experimental results are compared to fits obtained either with a crystal thickness that matches experimental data, or the one given by the company in the case of the RONTEC and ORTEC detectors. For the ORTEC detector no difference is found within the error bars confirming the characteristics provided by the manufacturer. For the RONTEC detector, the best fit is obtained for a crystal thickness of $240 \mu \mathrm{m}$, which is significantly lower than the value given by the manufacturer. Finally, the same methods have been applied to determine the efficiency of the KETEK model reported as well in table III and good agreement is found in this case with the crystal thickness specified by the manufacturer.

\section{FULL EFFICIENCY DETERMINATION AND CONCLUSION}

With the entire set of data presented above, we can summarize the few discrepancies found with the parameters provided by the manufacturers by comparing the thicknesses of each element playing a role in the detection efficiency of the three solid-state detectors 
investigated here (see Table III). For the RONTEC and KETEK detectors, the beryllium window thickness is found to be systematically larger than specified; a disagreement of a factor of two is almost reached in the case of the RONTEC detector. Moreover, it seems that the introduction of a very thin dead layer $(70 \pm 20 \mathrm{~nm})$ reproduces better the experimental $2 E 1$ spectrum in the case of the RONTEC, for which no dead layer was expected. Although special emphasis has been put on the minimization of the effective silicon dead layer by the manufacturer, the slight reduction of the efficiency might also be due to a non-structured $\mathrm{p}^{+}$junction cover of the entrance window (see Ref 15 for the detector description). For the KETEK detector, we can only give an upper limit value for the dead layer thickness since only efficiency measurements deduced from fluorescence x-ray yields have been performed. Regarding the crystal thickness, the experimental value found for the RONTEC detector is $20 \%$ lower than the manufacturer's data while good agreement within the error bars is obtained for the others. Figure 8 summarizes the complete detection efficiency for the three solid-state detectors.

In conclusion, we clearly demonstrate that such complete experimental studies are needed to check parameters provided by the manufacturers. Indeed, reliable values of the detection efficiency within a few $\%$ of uncertainty are mandatory to extract absolute cross sections of numerous processes giving rise to soft or hard X-ray emission such as those occurring during short laser pulses interacting with rare gas clusters, highly charged ions colliding with atoms, clusters, surfaces or solids or even to characterize plasma density and temperature in an ECR ion source. We have measured the efficiency of three silicon detectors among which two are based on the silicon drift detector technique. We 
showed that the detection of the $\operatorname{Ar}^{17+} 2 s \rightarrow 1 s$ transition and, especially, of the $2 E 1$ decay mode emission is a successful method to determine the detection efficiency at low photon energy. In fact, the precise theoretical knowledge of the $2 E 1$ energetic distribution offers the opportunity to accurately investigate the efficiency from 0 to around $3 \mathrm{keV}$ and provides a stringent test of both, the beryllium window thickness and possible very thin absorber layers lying in front of the sensitive crystal area. Finally, the use of a ${ }^{241} \mathrm{Am}$ source, which gives rise to photons in the $10-60 \mathrm{keV}$ range, enables a precise evaluation of the effective thickness of the detection crystal.

\section{Acknowledgment}

This work has been supported by the French national agency of research (ANR: Agence Nationale de Recherche) contract ANR 06 BLAN 0233. We thank the CIRIL platform of the CIMAP laboratory and the staff at GANIL for providing us with outstanding technical assistance and high-quality of highly-charged ion beams.

\footnotetext{
${ }^{1}$ E. Lamour, B. Gervais, J. P. Rozet, and D. Vernhet, Phys. Rev. A 73, 042715 (2006).

${ }^{2}$ M. Seliger, C. O. Reinhold, T. Minami, D. R. Schultz, M. S. Pindzola, S. Yoshida, J. Burgdörfer, E. Lamour, J. P. Rozet, and D. Vernhet, Phys. Rev. A 75, 032714 (2007).

${ }^{3}$ E. Lamour, C. Prigent, J. P. Rozet, and D. Vernhet, XXV International Conference on Photonic, Electronic and Atomic Collisions, Journal of Physics: Conference Series 88, 012035, (2007); C. Prigent, C. Deiss, E. Lamour, J. P. Rozet, J. Burgdörfer and D. Vernhet, Phys. Rev. A 78, 053201 (2008).
} 
${ }^{4}$ R P Gardner, A M Yacout, J Zhang, and K Verghese, Nucl. Instrum. Methods A 242, 399 (1986).

5 J. L. Campbell, Leonard McDonald, Theodore Hopman, and Tibor Papp, X-Ray Spectrom. 30, 230 (2001).

${ }^{6}$ F. Scholze and M. Procop, X-Ray Spectrom. 30, 69 (2001).

7 T. Eggert, O. Boslau, J. Kemmer, A. Pahlke, and F. Wiest, Nucl. Instrum. Methods Phys. Res. A 568, 1 (2006).

${ }^{8}$ A.G. Karydas, Ch.Zarkadas, A.Kyriakis, J. Pantazis, A. Huber, R. Redus, C. Potiriadis and T. Paradellis X-Ray Spectrom. 32, 93 (2003).

9 J. S. Hansen, J. C. McGeorge, D. Nix, W. D. Schmidt-Ott, I. Unus, and R. W. Fink, Nucl. Instrum. Methods 106, 365 (1973).

10 J. L. Campbell and P. L. McGhee, Nucl. Instrum. Methods Phys. Res. A 248, 393 (1986).

11 Joanne M O’Meara and John L. Campbell, X-Ray Spectrom. 33, 146 (2004).

${ }^{12}$ V. Peyres and E. Garcia-Torano, Nucl. Instrum. Methods Phys. Res. A 580, 296 (2007).

13 B. P. Mohanty, P. Balouria, M. L. Garg, T. K. Nandi, V. K. Mittal, and I. M. Govil, Nucl. Instrum. Methods Phys. Res. A 584, 186 (2008).

14 S. P. Goldman and G. W. Drake, Phys. Rev. A 24, 183 (1981). J. P. Santos, F. Parente, and P. Indelicato, Eur. Phys. J. D 3, 43 (1998). 
15 P. Lechner, C. Fiorini, R. Hartmann, J. Kemmer, N. Krause, P. Leutenegger, A.

Longoni, H. Soltau, D. Stötter, R. Stötter, L. Strüder, and U. Weber, Nucl. Instrum. Methods Phys. Res. A 458, 281 (2001).

${ }^{16}$ C. Prigent, Ph.D. Thesis, Université Pierre et Marie Curie-UPMC, 2004, http://tel.archives-ouvertes.fr/hal-00008123/en

${ }^{17}$ C. J. Bland, J. Morel, E. Etcheverry, and M. C. Lepy, Nucl. Instrum. Methods Phys. Res. A 312, 323 (1992).

18 David D. Cohen, Nucl. Instrum. Methods Phys. Res. A 267, 492 (1988).

19 M. Weksler and A. G. de Pinho, Rev. Brasil. Fis. 3, 291 (1973). 
TABLE I. Specifications of each detector provided by the manufacturers.

\begin{tabular}{|c|c|c|c|c|c|c|}
\hline \multirow[t]{2}{*}{ Detector } & \multicolumn{2}{|c|}{ crystal } & \multirow{2}{*}{$\begin{array}{l}\text { dead } \\
\text { layer }\end{array}$} & \multirow{2}{*}{$\begin{array}{l}\text { contact } \\
\text { layer }\end{array}$} & \multirow{2}{*}{$\begin{array}{l}\mathrm{Be} \\
\text { thickness }\end{array}$} & \multirow{2}{*}{$\begin{array}{l}\text { Energy } \\
\text { resolution }\end{array}$} \\
\hline & Thickness & Diameter & & & & \\
\hline RONTEC & $300 \mu \mathrm{m}$ & $2 \mathrm{~mm}$ & 0 & -- & $8 \mu \mathrm{m}$ & $140 \mathrm{eV}$ \\
\hline KETEK & $450 \mu \mathrm{m}$ & $10 \mathrm{~mm}$ & 0 & -- & $25 \mu \mathrm{m}$ & $140 \mathrm{eV}$ \\
\hline ORTEC & $5.53 \mathrm{~mm}$ & $10 \mathrm{~mm}$ & $0.1 \mu \mathrm{m}$ & $0.02 \mu \mathrm{m}$ & $25 \mu \mathrm{m}$ & $180 \mathrm{eV}$ \\
\hline
\end{tabular}


TABLE II. Energies, branching ratios for the $\mathrm{Np}_{\mathrm{L}}$ lines and $\gamma$-rays from the alpha decay of a ${ }^{241} \mathrm{Am}$ source and the relative detection efficiency deduced from eq(5) for the three detectors. The branching ratios are normalized to the $L_{\alpha}$ line (having an emission probability of $\mathbf{0 . 1 3 0}$ per disintegration); the reported values are consistent with those published in refs $17,18,19$ with an accuracy of $\pm 5 \% . L_{\alpha}=L_{\alpha 1}+L_{\alpha 2}$, $L_{\beta}(a)=L_{\beta 15}+L_{\beta 2}+L_{\beta 7}$ and $L_{\beta}(b)=L_{\beta 5}+L_{\beta 1}+L_{\beta 3}$. The fitted value of the sensitive zone of the crystal detector is reported on the last line.

\begin{tabular}{|c|c|c|c|c|c|}
\hline Line & $\begin{array}{c}\text { Energy } \\
(\mathrm{keV})\end{array}$ & $\begin{array}{l}\text { Normalized } \\
\text { branching } \\
\text { ratio }\left(\mathrm{I}_{\text {Line }}\right)\end{array}$ & RONTEC model & KETEK model & ORTEC model \\
\hline $\mathrm{L}_{1}$ & 11.89 & $6.0 \times 10^{-2}$ & $1.42 \pm 0.08$ & $1.28 \pm 0.07$ & $1.02 \pm 0.05$ \\
\hline $\mathrm{L}_{\alpha}$ & 13.90 & 1 & $1 \pm 0.05$ & $1 \pm 0.05$ & $1 \pm 0.05$ \\
\hline $\mathrm{L}_{\beta}(\mathrm{a})$ & 16.91 & $3.53 \times 10^{-1}$ & $0.67 \pm 0.04$ & $0.74 \pm 0.04$ & $1.02 \pm 0.05$ \\
\hline $\mathrm{L}_{\beta}(\mathrm{b})$ & 17.76 & 1.02 & $0.56 \pm 0.04$ & $0.67 \pm 0.03$ & $1.02 \pm 0.05$ \\
\hline $\mathrm{L}_{\gamma}$ & 20.79 & $3.75 \times 10^{-1}$ & $0.32 \pm 0.02$ & $0.45 \pm 0.02$ & -- \\
\hline$\gamma_{1}$ & 26.35 & $1.72 \times 10^{-1}$ & $0.20 \pm 0.01$ & $0.23 \pm 0.01$ & $0.89 \pm 0.05$ \\
\hline$\gamma_{2}$ & 33.20 & $9.04 \times 10^{-3}$ & -- & & $0.63 \pm 0.05$ \\
\hline$\gamma_{3}$ & 43.42 & $4.80 \times 10^{-3}$ & -- & & $0.37 \pm 0.02$ \\
\hline$\gamma_{5}$ & 59.54 & 2.66 & -- & & $0.16 \pm 0.01$ \\
\hline $\begin{array}{c}\text { Fitted crystal } \\
\text { thickness }\end{array}$ & & & $\mathrm{x}_{\mathrm{sz}}=240 \pm 1 \mu \mathrm{m}$ & $\mathrm{x}_{\mathrm{sz}}=450 \pm 2 \mu \mathrm{m}$ & $\mathrm{x}_{\mathrm{sz}}=5755 \pm 350 \mu \mathrm{m}$ \\
\hline
\end{tabular}


TABLE III. Thickness of each element playing a role in the calculation of the detection efficiency for the three detectors studied: exp.value for the experimental value extracted from the measurements; man.spec. for the specifications provided by the manufacturer. For the KETEK detector, just an upper value of the dead layer (*) is reported since it has been deduced only from fluorescence measurements (see text). It is worth mentioning that a gold layer has to be taken into account for the ORTEC Si(Li) detector and is found to be equal to $0.020 \pm 0.005 \mu \mathrm{m}$.

\begin{tabular}{lcccccc}
\hline \hline Detector & \multicolumn{2}{c}{ Be thickness $\mathrm{x}_{\mathrm{Be}}(\mu \mathrm{m})$} & \multicolumn{2}{c}{ dead layer $\mathrm{x}_{\mathrm{dl}}(\mu \mathrm{m})$} & \multicolumn{2}{c}{ sensitive zone $\mathrm{x}_{\mathrm{sz}}(\mu \mathrm{m})$} \\
\hline \hline & exp.value & man.spec. & exp.value & man.spec. & exp.value & man.spec. \\
RONTEC & $15 \pm 1$ & 8 & $0.07 \pm 0.02$ & 0 & $240 \pm 1$ & 300 \\
KETEK & $34 \pm 3$ & 25 & $<0.05^{(*)}$ & 0 & $450 \pm 2$ & 450 \\
ORTEC & $26.5 \pm 0.5$ & 25 & $0.10 \pm 0.03$ & 0.1 & $5755 \pm 350$ & 5530 \\
\hline \hline
\end{tabular}


FIG 1. (Color online) Energy distribution of the $2 E 1$ decay mode for $\mathrm{Ar}^{17+}$. The theoretical distribution: dotted line; the expected experimental distributions for three cases (two different Be windows and dead layer, respectively $\mathrm{x}_{\mathrm{Be}}$ et $\mathrm{x}_{\mathrm{dl}}$ ): dashdotted line with $x_{\mathrm{Be}}=8 \mu \mathrm{m}$ and $x_{\mathrm{dl}}=0$, dashed line with $\mathrm{x}_{\mathrm{Be}}=15 \mu \mathrm{m}$ and $\mathrm{x}_{\mathrm{dl}}=0$ and red solid line $x_{\mathrm{Be}}=15 \mu \mathrm{m}$ and $\mathrm{x}_{\mathrm{dl}}=0.07 \mu \mathrm{m}$. Note that the experimental distributions take into account the convolution with the detector resolution.

FIG 2. (Color online ) Spectra of the $2 s \rightarrow 1 s$ transition recorded by the RONTEC detector placed at $50 \mathrm{~mm}$ behind the target (green thin solid line). Fits have been obtained using a dead layer $\left(x_{\mathrm{dl}}\right)$ of $0.07 \mu \mathrm{m}$ and three different Be window thicknesses $\left(\mathrm{x}_{\mathrm{Be}}\right)$ to calculate the detection efficiency with formula (2).

FIG 3. (Color online) Spectra of the $2 s \rightarrow 1 s$ transition recorded by the RONTEC detector placed at $50 \mathrm{~mm}$ behind the target (green thin solid line). Fits have been obtained using a unique Be window thickness of $15 \mu \mathrm{m}$ and two different dead layer thicknesses $\left(x_{d l}\right)$ to calculate the detection efficiency with formula (2).

FIG 4. (Color online) Efficiency of the RONTEC detector in the 0-6 keV photon energy range: dashed line corresponds to the expected efficiency according to the manufacturer's specifications; green solid line with error bars is the fitted curve 
obtained with eq(2) for $x_{B e}=15 \pm 1 \mu \mathrm{m}$ and $x_{d l}=0.07 \pm 0.03 \mu \mathrm{m}$ that have been determined via the $2 E 1$ energy distribution (see text and Fig. 2 and 3); circles symbolize the measured efficiencies using fluorescence emission.

FIG 5. (Color online) Typical spectrum recorded by the ORTEC detector showing the $\mathrm{Np} \mathrm{X}_{\mathrm{L}}$ lines and $\gamma$-rays coming from alpha decay of a ${ }^{241} \mathrm{Am}$ source. Also clearly visible is the "shelf" due to Compton scattering.

FIG 6. (Color online) Spectrum of the 10 to $25 \mathrm{keV}$ energy region recorded with a ${ }^{241}$ Am placed in front of the ORTEC (blue) and RONTEC (green) detectors. Note that the Compton scattering contribution has been subtracted in both cases.

FIG 7. (Color online) Efficiency of two different detectors (RONTEC and ORTEC models) for photon energy $>10 \mathrm{keV}$. For the RONTEC detector (in green), the circles symbolize the experimental efficiency values, the solid line corresponds to the best fit obtained with $x_{\mathrm{sz}}=240 \mu \mathrm{m}$; the black dashed line is the efficiency calculated with the manufacturer's crystal thickness. For the ORTEC detector (in blue), the square symbols are the experimental data and the dash-dotted line the best fit, which is in agreement with the manufacturer specification.

FIG 8. (Color online) Efficiency over the entire energy range of detection based on the different experimental methods for the three detectors under investigation. 
Symbols correspond to the experimental data: circles for the RONTEC detector (in green); triangles for the KETEK detector (in red) and squares for the ORTEC one (in blue). Lines display the best fit calculated with the parameters extracted from experiments and given in Table III. 